\title{
Effect of Storage of Tulobuterol Tapes after Package Opening and Liner Peeling on Their Formulation Properties
}

\author{
Ayumi Iwanami, ${ }^{a}$ Misuzu Ota, ${ }^{a, b}$ Shinji Hidaka, ${ }^{c}$ Miyuki Tajima, ${ }^{b}$ Hiraku Onishi, ${ }^{a}$ and Yuri Ikeuchi-Takahashi ${ }^{*}, a$ \\ ${ }^{a}$ Department of Drug Delivery Research, Hoshi University; 2-4-41 Ebara, Shinagawa-ku, Tokyo 142-8501, Japan: \\ bJuntendo Tokyo Koto Geriatric Medical Center; 3-3-20 Shinsuna, Koto-ku, Tokyo 136-0075, Japan: and \\ 'School of Pharmacy, Nihon University; 7-7-1 Narashinodai, Funabashi, Chiba 274-8555, Japan.
}

(Received December 7, 2020; Accepted April 8, 2021)

\begin{abstract}
Although tulobuterol tape is provided to patients in an inner package, information regarding the stability of the tape after opening the packaging may be requested by patients. This study was performed to generate underlying data on the storage stability after package opening or liner peeling with package opening. Tulobuterol tapes were stored at $25^{\circ} \mathrm{C}$, $60 \%$ relative humidity $(\mathrm{RH}) ; 40^{\circ} \mathrm{C}, 75 \% \mathrm{RH}$; or in a refrigerator $\left(2-4{ }^{\circ} \mathrm{C}, 10-30 \% \mathrm{RH}\right)$ for 1 day or 3 days. In a peel adhesive strength test after package opening, storage at $25^{\circ} \mathrm{C}, 60 \% \mathrm{RH}$ had a low effect on the adhesive strength of the tape. Storage after liner peeling with package opening resulted in variable adhesive strength of the tape. Regarding drug release properties, for storage after package opening, the $f 2$ values of tapes stored in the three different conditions were over 50 , except for tapes stored at $25^{\circ} \mathrm{C}, 60 \% \mathrm{RH}$ for 3 days. For the tapes stored at $25^{\circ} \mathrm{C}, 60 \% \mathrm{RH}$ or $40^{\circ} \mathrm{C}, 75 \% \mathrm{RH}$ after liner peeling with package opening, the release rate and the ratio of drug released at $24 \mathrm{~h}$ may be decreased because the drug content decreased due to drug sublimation. This study suggested that tulobuterol tapes can be stored after package opening at $25^{\circ} \mathrm{C}, 60 \% \mathrm{RH}$ for $1 \mathrm{~d}$.
\end{abstract}

Key words—— transdermal drug delivery; tulobuterol tape; storage stability; package opening; liner peeling

\section{INTRODUCTION}

Transdermal therapeutic systems (TTS) have various advantages. They can be utilized by patients who have difficulty in oral administration, the pain and burden on patients are less than that of an injection, hepatic first-pass metabolism can be avoided, it is easy to maintain the plasma drug concentrations at the required level, and it is simple to discontinue the administration and to confirm the medication. ${ }^{1-3)}$ TTS can be expected to improve patient compliance by reducing side effects, and they can be applied to children and the elderly. ${ }^{4,5)}$

Tulobuterol is a sympathetic $\beta_{2}$ receptor agonist used in the treatment of asthma, bronchitis, emphysema, etc. $\left.{ }^{6}\right)$ Tulobuterol tapes, which allow the active ingredient to be absorbed through the skin, can maintain a long duration of action. ${ }^{7)}$ This is convenient for controlling seizures at dawn. Because tulobuterol tape $\left(\right.$ Hokunalin $^{\circledR}$ ) can provide $\beta_{2}$ agonist activity for 24 $\mathrm{h}$, it is widely used by children. ${ }^{8,9)}$ Regarding tulobuterol tape, medicines information is given mainly on safety-related matters by pharmacists. In other words, information on side effects, the site of

\footnotetext{
*e-mail: y-ikeuchi@hoshi.ac.jp
}

application and replacement every $24 \mathrm{~h}$ is provided with the highest priority. Besides, the pharmacists explain storing the tape avoiding direct sunlight, high temperature and humidity, and storing it in an inner package. However, especially for children, the tape may not be applied to the patient immediately after opening the package if the child is not willing to have the tape applied. Patients may also forget to apply the tape after opening the package. It is considered that the explanation about the storage condition after opening the inner package is not sufficient, and information is sometimes requested by patients regarding the stability of the tape after opening the package. Although information on the stability of tapes packed in the inner package is provided by the manufacturer, there is not enough information on the stability after opening the inner package or peeling the liner. ${ }^{10)}$ Hence, this study was performed to generate underlying data on the storage stability of tulobuterol tapes after opening the inner package to explain to patients. Tulobuterol tape (Hokunalin ${ }^{\circledR}$ ) was used as the test formulation. The tapes were stored in various conditions after package opening or liner peeling with package opening, and the formulation properties were evaluated over time. 


\section{MATERIALS AND METHODS}

Materials Tulobuterol tape (Hokunalin ${ }^{\circledR}$ tape $2 \mathrm{mg}$ ) was purchased from Mylan EPD G.K. (Tokyo). 0.9\% sodium chloride solution was obtained from Otsuka Pharmaceutical Co., Ltd. (Tokyo). Sodium 1-octanesulfonate was obtained from Tokyo Chemical Industry Co., Ltd. (Tokyo). All other chemicals were obtained commercially as the purest grade available.

Storage Conditions The tulobuterol tapes were stored at (1) $25^{\circ} \mathrm{C}, 60 \%$ relative humidity $(\mathrm{RH}),(2)$ $40^{\circ} \mathrm{C}, 75 \% \mathrm{RH}$, and (3) in a refrigerator $\left(2-4^{\circ} \mathrm{C}, 10\right.$ $30 \% \mathrm{RH})$. After package opening or liner peeling with package opening, the tapes were stored for $1 \mathrm{~d}$ or $3 \mathrm{~d}$ in the three storage conditions.

Adhesive Strength Test The adhesive strength of the tulobuterol tapes was measured in accordance with the peel adhesive strength test method of the Japanese Pharmacopoeia 17 (JP17).11,12) A tulobuterol tape was attached to a test plate (SSP-1608, Imada Co., Ltd., Toyohashi) using a rubber roller for the peel test (APR-97, $2 \mathrm{~kg}$, Imada Co., Ltd., Toyohashi). The tape was adhered to the test plate using a rubber roller by one back and forth movement at a speed of about $5 \mathrm{~mm} / \mathrm{s}$, and folded back at $180^{\circ}$ by gripping the edge of the tape so that the backing side overlapped. A FUDOH rheometer (RTC-3005D, Leotech Co., Ltd., Tokyo) set adapter No. 17 was used, and the gripping edge of the tape was fixed to the upper part and the test plate was fixed to the lower part. The lower part of the rheometer was moved down at a speed of $30 \mathrm{~cm} / \mathrm{min}$ to measure the strength of the tape as it peeled off the test plate. After the start of the measurement, the first $25 \%$ length of the measurement was ignored, and the next $50 \%$ length measurement was averaged, and the average value was determined as the peel adhesive strength test value $(\mathrm{N})$.

In Vitro Drug Release Experiments The in vitro drug release from the tulobuterol tape was examined using a Franz diffusion cell. ${ }^{13,14)}$ As a receiver solution, $0.9 \%$ sodium chloride solution was used. ${ }^{15)}$ The volume of the receptor chamber was $12 \mathrm{~mL}$ and the exposed area of the Franz diffusion cell was $1.77 \mathrm{~cm}^{2}$. The receiver solution in the chamber was stirred with a magnetic stirrer at a speed of $700 \mathrm{rpm}$ and maintained at $32 \pm 1^{\circ} \mathrm{C}$. Tulobuterol tape was mounted between the donor and receiver compartments of the
Franz diffusion cell so that the drug release surface contacted with the receiver solution. Samples (0.4 $\mathrm{mL}$ ) of the receptor solution were taken at predetermined time intervals $(0.5,1,2,3,4,5,24 \mathrm{~h})$, and replaced with fresh receiver solution. The sample solution was diluted with $0.9 \%$ sodium chloride solution and the absorbance at $215 \mathrm{~nm}$ was measured using a UV spectrophotometer (UV-1800, Shimadzu Corporation, Kyoto) for evaluation of the amount of drug released. The ratio (\%) of the amount of released drug to the amount of drug contained in the exposed area was determined.

Similarity Factor In order to measure the similarity of the drug release profiles, a similarity factor $(f 2)$ was calculated from the following equation. ${ }^{16,17)}$

$$
f 2=50 \cdot \log \left\{\left[1+(1 / \mathrm{n}) \sum_{\mathrm{i}=1}^{\mathrm{n}}(\mathrm{Ti}-\mathrm{Ri})^{2}\right]^{-0.5} \cdot 100\right\}
$$

Here, $\mathrm{Ti}$ is the average drug release ratio from the tape before storage, and $\mathrm{Ri}$ is the average drug release ratio from the tape after storage. $\mathrm{n}$ is the number of the sampling times, and here it was calculated as $n=$ 7.

Measurement of Drug Recovery Amounts After removing the liner for tapes with a liner, the tulobuterol tapes before or after storage were soaked in methanol $(23 \mathrm{~mL})$ in a glass container with a cap and stirred for $24 \mathrm{~h}$ at $30^{\circ} \mathrm{C}$ and $60 \mathrm{rpm}$. Then, the methanol solution was collected in a volumetric flask and made up to $25 \mathrm{~mL}$ with methanol. This solution was further diluted with methanol, filtered through a membrane filter $(0.45 \mu \mathrm{m})$, and then a $20 \mu \mathrm{L}$ aliquot of the filtrate was injected into HPLC system. The HPLC system consisted of a LC-6AD pump (Shimadzu Corporation, Kyoto) and an SPD-20AV UV detector (Shimadzu Corporation) equipped with a Capcell Pak C18 MG II column $(4.6 \times 250 \mathrm{~mm}$, OSAKA SODA Co., Ltd., Osaka). A ChromatoPRO (Run Time Corporation, Tokyo) was used for chromatogram data processing. Chromatography was carried out at $40^{\circ} \mathrm{C}$. An aqueous solution of the mobile phase was prepared by dissolving sodium 1octanesulfonate $(3 \mathrm{~g})$ in water $(900 \mathrm{~mL})$ and adding $5 \mathrm{~mL}$ of diluted phosphoric acid $(1 \rightarrow 150)$. Acetonitrile $[35 \%(\mathrm{v} / \mathrm{v})]$ in the aqueous solution was prepared as the mobile phase. The flow rate was $1 \mathrm{~mL} /$ min, and the detection wavelength was $215 \mathrm{~nm}$.

The drug concentration was determined from the peak area of HPLC using a calibration curve, and the 
drug recovery amounts in the preparations were determined. Furthermore, the drug recovery amount ratio was calculated from the following formula.

Drug recovery amount ratio $=$

Drug recovery amount after storage/

Drug recovery amount before storage

Statistical Evaluation Statistical analysis was performed using Student's $t$-test. The software used was BellCurve for Excel (Social Survey Research Information Co., Ltd., Tokyo). The level of significance was taken as $p<0.05$.

\section{RESULTS}

Peel Adhesive Strength Test Value Peel adhesive strength test values of tulobuterol tapes before or after storage are shown in Fig. 1. For tapes stored in a refrigerator after package opening, the values increased significantly after $1 \mathrm{~d}$ and $3 \mathrm{~d}$ compared with before storage. For the tapes stored in the refrigerator after liner peeling with package opening, a significant change was not observed after $1 \mathrm{~d}$ and $3 \mathrm{~d}$ but the variability increased. For the tapes stored at $25^{\circ} \mathrm{C}$, $60 \% \mathrm{RH}$, no significant change was observed after package opening or liner peeling with package opening compared with before storage. However, variability of values in the tapes after liner peeling with package opening observed. For the tapes stored at $40^{\circ} \mathrm{C}$, $75 \% \mathrm{RH}$, a significant increase was observed after package opening after $3 \mathrm{~d}$, and a significant decrease was observed after liner peeling with package opening after $1 \mathrm{~d}$ and $3 \mathrm{~d}$.

Drug Release Experiments The drug release profiles from tulobuterol tapes before or after storage are shown in Fig. 2. $f 2$ values are an indicator of the similarity of the drug release profiles. The $f 2$ values are shown in Table 1. For tapes stored in the refrigerator after package opening, although the release rate was slightly slower, the ratio of drug released at $24 \mathrm{~h}$ was similar compared with before storage, and the $f 2$ values were over 50 . For tapes stored in the refrigerator after liner peeling with package opening, the release rate and the ratio of drug released at $24 \mathrm{~h}$ were slightly lower. Although the $f 2$ value after storage for $1 \mathrm{~d}$ was over 50 , the value after storage for $3 \mathrm{~d}$ was less than 50 . For the tapes stored at $25^{\circ} \mathrm{C}, 60 \% \mathrm{RH}$ after package opening, although the release rate and the ratio of drug released at $24 \mathrm{~h}$ were slightly lower, the $f 2$ value after storage for $1 \mathrm{~d}$ was over 50 . However, the value after storage for $3 \mathrm{~d}$ was less than 50 . On the (a)

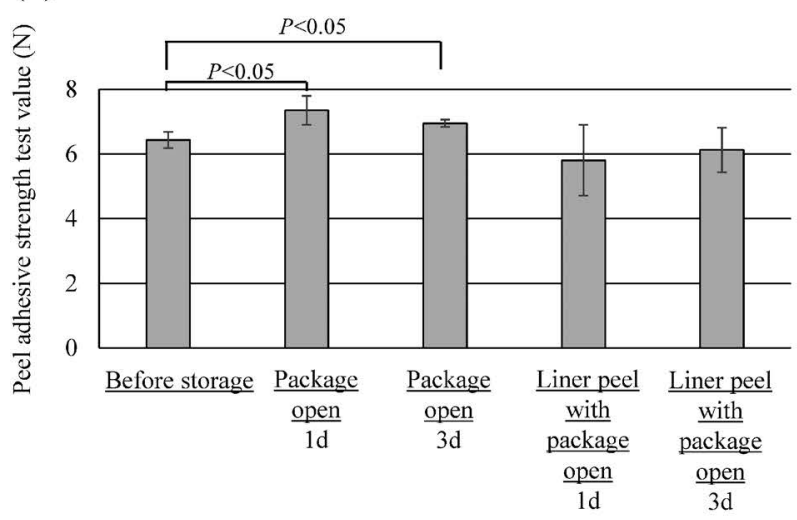

(b)

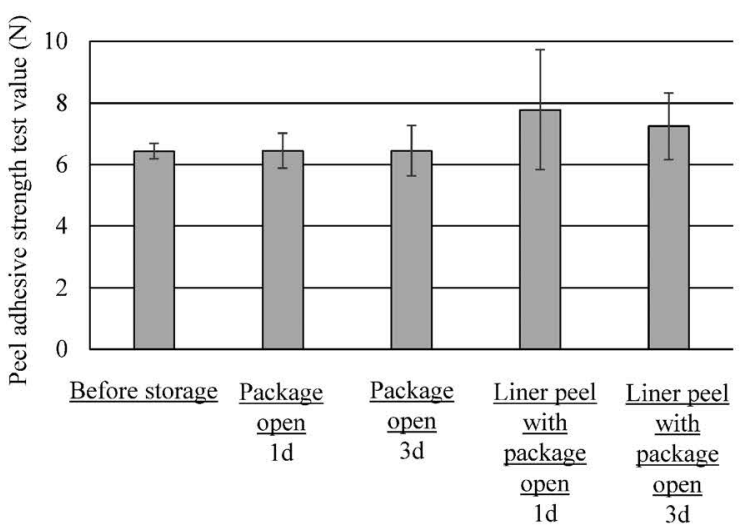

(c)

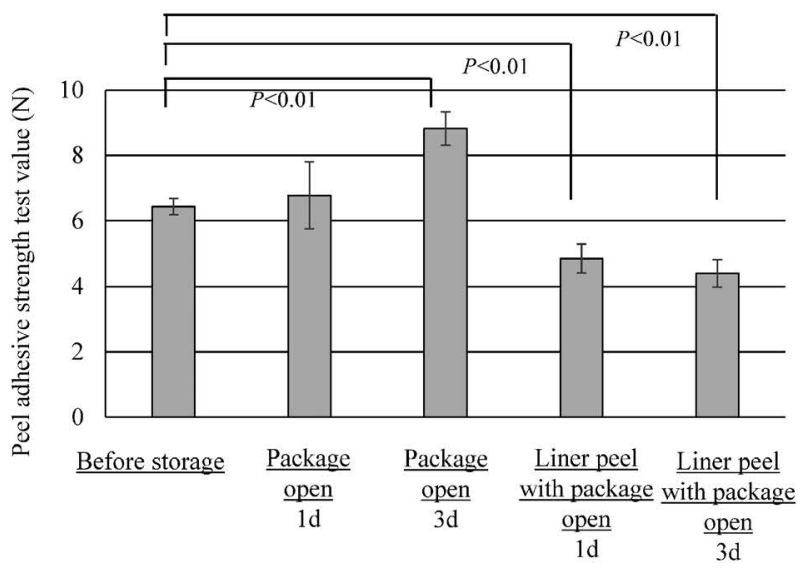

Fig. 1. Peel Adhesive Strength Test Values of Tulobuterol Tapes before or after Storage

(a) Refrigerator, (b) $25^{\circ} \mathrm{C}, 60 \% \mathrm{RH}$, (c) $40^{\circ} \mathrm{C}, 75 \% \mathrm{RH}$. Each value represents the mean \pm S.D. $(n=4)$.

other hand, for tapes stored at $25^{\circ} \mathrm{C}, 60 \% \mathrm{RH}$ after liner peeling with package opening, the release rate and the ratio of drug released at $24 \mathrm{~h}$ were decreased. The ratios of drug released at $24 \mathrm{~h}$ were $75 \%$ and $59 \%$ after $1 \mathrm{~d}$ and $3 \mathrm{~d}$, respectively. For tapes stored for $1 \mathrm{~d}$ and $3 \mathrm{~d}$ at $40^{\circ} \mathrm{C}, 75 \% \mathrm{RH}$ after package opening, the 
(a)

(b)

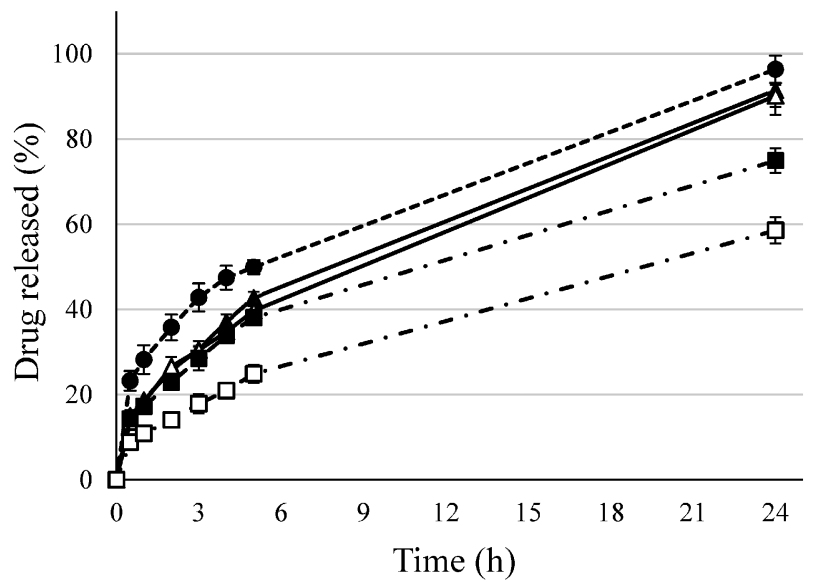

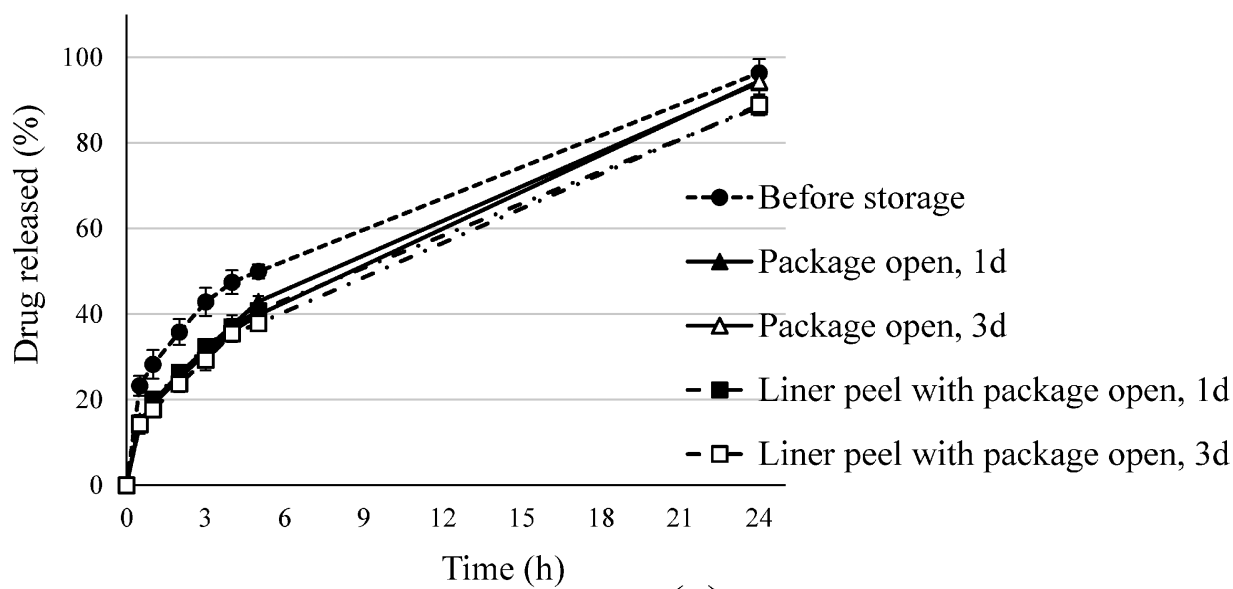

(c)

Fig. 2. Drug Release Profiles from Tulobuterol Tapes before or after Storage

(a) Refrigerator, (b) $25^{\circ} \mathrm{C}, 60 \% \mathrm{RH}$, (c) $40^{\circ} \mathrm{C}, 75 \% \mathrm{RH}$. Each point represents the mean \pm S.D. $(n=3)$.

Table 1. Similarity Factor $(f 2)$ of Tulobuterol Tape after Storage

\begin{tabular}{lccc}
\hline \hline & \multicolumn{3}{c}{$f 2$} \\
\cline { 2 - 4 } & Refrigerator & $25^{\circ} \mathrm{C}, 60 \% \mathrm{RH}$ & $40^{\circ} \mathrm{C}, 75 \% \mathrm{RH}$ \\
\hline Package open, 1 d & 52.8 & 51.7 & 76.8 \\
Package open, 3 d & 50.6 & 49.3 & 67.4 \\
Liner peeled with package open, 1 d & 51.7 & 42.7 & 21.5 \\
Liner peeled with package open, 3 d & 47.5 & 30.1 & 16.0 \\
\hline
\end{tabular}

release rate and the ratio of drug released at $24 \mathrm{~h}$ were similar compared with before storage, and the $f 2$ values were over 50. On the other hand, for the tapes stored at $40^{\circ} \mathrm{C}, 75 \% \mathrm{RH}$ after liner peeling with package opening, the release rate and the ratio of drug released at $24 \mathrm{~h}$ were obviously decreased. The ratios of drug released at $24 \mathrm{~h}$ were $25 \%$ and $5 \%$ after $1 \mathrm{~d}$ and $3 \mathrm{~d}$, respectively.

Drug Recovery Amount The drug recovery amount from the tulobuterol tape before storage was $90.1 \pm 1.5 \%(n=3)$. The drug recovery ratios (drug recovery amount after storage/drug recovery amount before storage) are shown in Table 2. For the tapes stored in three different conditions for $1 \mathrm{~d}$ after package opening, the drug recovery amount ratio was over 0.95 . The drug recovery amount ratio for tapes stored in the refrigerator for $1 \mathrm{~d}$ after liner peeling with package opening was 0.98 . However, for the tapes stored at $25^{\circ} \mathrm{C}, 60 \% \mathrm{RH}$ or $40^{\circ} \mathrm{C}, 75 \% \mathrm{RH}$ for $1 \mathrm{~d}$ after liner peeling with package opening, the drug recovery amount ratios were decreased. 
Table 2. Drug Recovery Ratio from Tulobuterol Tape

\begin{tabular}{lccc}
\hline \hline & \multicolumn{3}{c}{ Drug recovery amount ratio } \\
\cline { 2 - 4 } & Refrigerator & $25^{\circ} \mathrm{C}, 60 \% \mathrm{RH}$ & $40^{\circ} \mathrm{C}, 75 \% \mathrm{RH}$ \\
\hline Package open, 1 d & $1.00 \pm 0.03$ & $0.98 \pm 0.01$ & $0.95 \pm 0.02$ \\
Liner peeled with package open, 1 d & $0.98 \pm 0.02$ & $0.74 \pm 0.02$ & $0.30 \pm 0.04$ \\
\hline
\end{tabular}

Each value represents the mean \pm S.D. $(n=3)$.

\section{DISCUSSION}

The stability of a pharmaceutical formulation should be assured even after it has been handed over to the patient. ${ }^{18)}$ Thus, we investigated whether the stability of tulobuterol tape was assured after opening the inner package or after peeling the liner with opening the inner package. In JP17, it is stated that tulobuterol gradually sublimates at $40^{\circ} \mathrm{C}$. Hence, a decrease in tulobuterol content was predicted to occur with storage at high temperatures. In this study, tulobuterol tapes were stored in the refrigerator or at $25^{\circ} \mathrm{C}, 60 \% \mathrm{RH}$ in order to find conditions that could ensure the stability of the tapes after package opening. Furthermore, a stability test was conducted at $40^{\circ} \mathrm{C}, 75 \% \mathrm{RH}$, which are conditions for an accelerated stability test, ${ }^{19,20)}$ to investigate the effect of elevated temperature and humidity.

For the peel adhesive strength test values, the values of the tapes stored in a refrigerator or at $40^{\circ} \mathrm{C}$, $75 \% \mathrm{RH}$ increased after package opening. The adhesive strength of tapes stored after package opening may increase in high temperature or low humidity conditions. From these results, for the storage of tulobuterol tapes after package opening, it is suggested that storage conditions of $25^{\circ} \mathrm{C}, 60 \% \mathrm{RH}$ had little effect on the adhesive strength of the tapes. For tapes stored in the refrigerator or at $25^{\circ} \mathrm{C}, 60 \% \mathrm{RH}$ after liner peeling with package opening, the peel strength values became variable. For the tapes stored at $40^{\circ} \mathrm{C}$, $75 \%$ RH after liner peeling with package opening, the peel strength value decreased. This was thought to be due to dampness caused by the high humidity. From the results, it was suggested that the adhesive strength of the tapes stored after liner peeling with package opening is variable.

As for the drug release properties, the $f 2$ values of the tapes stored in three different conditions at $1 \mathrm{~d}$ after package opening were over 50. The U.S. Food and Drug Administration (FDA) defines that two elution profiles are equivalent when the value of the $f 2$ func- tion is between 50 and $100 .{ }^{21)}$ However, the $f 2$ values of the tapes stored at $25^{\circ} \mathrm{C}, 60 \% \mathrm{RH}$ for $3 \mathrm{~d}$ after package opening were less than 50. On the other hand, for the tapes stored after liner peeling with package opening, the $f 2$ values were less than 50 in all conditions except when stored in the refrigerator for $1 \mathrm{~d}$. For the tapes stored at $25^{\circ} \mathrm{C}, 60 \% \mathrm{RH}$ or $40^{\circ} \mathrm{C}$, $75 \% \mathrm{RH}$ after liner peeling with package opening, the release rate and the ratio of drug released at $24 \mathrm{~h}$ were markedly decreased. For tapes stored at $25^{\circ} \mathrm{C}, 60 \%$ RH for $1 \mathrm{~d}$ after liner peeling with package opening, the ratio of drug released at $24 \mathrm{~h}$ was $75 \%$, and this value was comparable to the drug recovery ratio (0.74). Similarly, for tapes stored at $40^{\circ} \mathrm{C}, 75 \% \mathrm{RH}$ for $1 \mathrm{~d}$ after liner peeling with package opening, the ratio of drug released at $24 \mathrm{~h}$ was $25 \%$, and this value was comparable to the drug recovery ratio $(0.30)$. From these results, for tapes stored at $25^{\circ} \mathrm{C}, 60 \% \mathrm{RH}$ or $40^{\circ} \mathrm{C}, 75 \% \mathrm{RH}$ after liner peeling with package opening, the release rate and the ratio of drug released at $24 \mathrm{~h}$ should be decreased by the drug content decrease due to drug sublimation. It is indicated that drug sublimation will occur from tulobuterol tapes stored at least $25^{\circ} \mathrm{C}$ after liner peeling with package opening. Sublimation of the drug could be suppressed by storage in a refrigerator, but when stored in the refrigerator, the variation in the adhesive strength increased. Thus, it is recommended not to use tape stored after liner peeling with package opening.

In the Hokunalin ${ }^{\circledR}$ tape interview form, ${ }^{22)}$ for tapes stored at $50^{\circ} \mathrm{C}$ for 3 months after package opening, it is stated that change in release rate and decrease in content due to volatilization were observed. Hence, even if the tapes before liner peeling, it is confirmed that the content decreases when stored at $40^{\circ} \mathrm{C}$ or higher for a long period of time. For tapes stored at $25^{\circ} \mathrm{C}, 90 \% \mathrm{RH}$ for 3 months after package opening, it is stated that change in the peel adhesive strength, the drug release rate and the content were not observed. Regarding the adhesive strength, it is stated that "the 
result of the peel adhesive strength test method (JP17) was $250 \mathrm{~g}$ or more". Under all three conditions stored in this study, the peel adhesive strength test values after storage for $3 \mathrm{~d}$ were $250 \mathrm{~g}$ or more. However, when the significance test was performed, there were some significant differences compared to the value before storage. Hence, it is considered that we need to pay attention to them. The release properties were evaluated using the $f 2$ values. The $f 2$ value has been applied to the drug release from tablets, and its application to transdermal preparations is under consideration. For tapes after package opening, the drug released in $24 \mathrm{~h}$ was $90 \%$ or more under all storage conditions. The evaluation using the $f 2$ value may be strict, but it is considered to pay attention to changes in the drug release profiles. Since the storage condition in the interview form is $25^{\circ} \mathrm{C}$ and $90 \% \mathrm{RH}$, which is different from the storage conditions in this study, it is necessary to further investigate the effects of different humidity.

This study suggested that tulobuterol tapes can be stored after package opening at $25^{\circ} \mathrm{C}, 60 \% \mathrm{RH}$ for $1 \mathrm{~d}$. Regarding the tulobuterol tape, it is necessary to instruct the patients to use it immediately after opening the inner package. However, if it cannot be applied immediately after opening the inner package, it can be suggested that the tapes before liner peeling are used within $24 \mathrm{~h}$ by storing away from high temperature and high humidity or low humidity.

Conflict of Interest The authors declare no conflict of interest.

\section{REFERENCES}

1) Marwah H., Garg T., Goyal A. K., Rath G., Drug Deliv., 23, 564-578 (2016).

2) Gato K., Shikaku R., Kato S., YoshimuraFujii M., Koide T., Fukami T., Yakugaku Zasshi, 140, 1175-1183 (2020).

3) Mofidfar M., O'Farrell L., Prausnitz M. R., J. Control. Release, 301, 140-145 (2019) .

4) McConville J., Drug Dev. Ind. Pharm., 42, 845 (2016).

5) Murakami Y., Sekijima H., Fujisawa Y., Ooi K., Biol. Pharm. Bull., 42, 586-593 (2019).

6) Watanabe T., Satoh H., Hori S., Miki A., Ohtani H., Sawada Y., Yakugaku Zasshi, 131, 1483-1492 (2011).

7) Tamura G., Ichinose M., Fukuchi Y.,
Miyamoto T., Allergol. Int., 61, 219-229 (2012) .

8) Katsunuma T., Fujisawa T., Nagao M., Akasawa A., Nomura I., Yamaoka A., Kondo H., Masuda K., Yamaguchi K., Terada A., Ikeda M., Nishioka K., Adachi Y., Kurihara K., Allergol. Int., 62, 37-43 (2013) .

9) Horiguchi T., Kondo R., Miyazaki J., Fukumokto K., Torigoe H., Arzneimittelforschung, 54, 280-285 (2004).

10) Hori K., Yoshida N., Okumura T., Okamura Y., Kawakami J., Yakugaku Zasshi, 130, 1029 -1040 (2010)

11) Miyazaki T., Kanno H., Aso Y., Goda Y., Yakugaku Zasshi, 138, 1425-1433 (2018).

12) Cilurzo F., Gennari C. G., Selmin F., Franzé S., Musazzi U. M., Minghetti P., Drug Dev. Ind. Pharm., 41, 183-189 (2015).

13) Tojo K., Hikima T., Biol. Pharm. Bull., 30, 1576-1579 (2007).

14) Takizawa Y., Goto T., Sato S., Ohmori N., Mori K., Shimada Y., Chen K., Miyagi T., Fukai F., Drug Discov. Ther., 11, 253-258 (2017).

15) Suzuki T., Sakisako Y., Kurihara Y., Aoki T., Kanematsu T., Todo H., Sugibayashi K., Chem. Pharm. Bull., 66, 851-858 (2018).

16) Ishitsuka K., Onuki Y., Takayama K., Yakugaku Zasshi, 132, 225-230 (2012).

17) Nguyen C., Christensen J. M., Ayres J. W., Pharm. Dev. Technol., 19, 10-20 (2014).

18) Wu Z., Pharm. Dev. Technol., 23, 941 (2018).

19) Fitzpatrick S., McCabe J. F., Petts C. R., Booth S. W., Int. J. Pharm., 246, 143-151 (2002).

20) Song Z., Sarkar S., Vogt A. D., Danzer G. D., Smith C. J., Gualtieri E. J., Simpson G. J., Anal. Chem., 90, 4406-4413 (2018).

21) U.S. Food and Drug Administration (FDA), Guidance for Industry: Dissolution Testing of Immediate Release Solid Oral Dosage Forms, FDA, Rockville, 1997.

22) Mylan EPD G.K., Hokunalin ${ }^{\circledR}$ tape interview form, 2017: 〈https://www.mylan.co.jp/-/ media/MylanJP / documents / epd_products / interview_updated/if_hokunalin_t.pdf $\rangle$, cited 12 February, 2021. 